\title{
Evaluating of Nutrient Composition and Pellet Durability Index on Pellet Supplement with Different Proportion of Protected Soybean Meal (P-SBM) and Selenium (Se)
}

\author{
Andriyani Astuti ${ }^{1}$, Rochijan Rochijan ${ }^{2}$, Budi Prasetyo Widyobroto ${ }^{2, *}$ and Lies Mira \\ Yusiati $^{1}$ \\ ${ }^{1}$ Department of Animal Nutrition and Feed Science, Faculty of Animal Science, Univeritas Gadjah Mada, Jl. Fauna \\ No. 3, Bulaksumur, Yogyakarta 55281 - Indonesia \\ 2 Department of Animal Production, Faculty of Animal Science, Univeritas Gadjah Mada, Jl. Fauna No. 3, \\ Bulaksumur, Yogyakarta 55281 - Indonesia \\ *Corresponding author. Email: budi_widyobroto@ugm.ac.id
}

\begin{abstract}
Pelleting process is one of production costs, and good processing pellets result in higher cost. Even though it is costly, pellet has convenience in feed handling and an increased efficient use of the feed by the animal. By heat processing, it reduces pathogens and increases the digestible starches, which improve feed efficiency. A significant portion of the improvement is related to the physical form of the pellet. The nutrient composition and pellet durability index (PDI) of six group pellet supplement samples with a different proportion of protected soybean meal (P-SBM) and selenium (Se) for dairy cattle feeding was determined. Feed samples were taken and analyzed in the Laboratory of Animal Feed Technology, Faculty of Animal Science Universitas Gadjah Mada. The observed variables were nutrient composition i.e. dry matter (DM), organic matter (OM), crude protein (CP), ether extract (EE), crude fibre (CF), and total digestible nutrients (TDN), PDI and physical or dimensions (diameter and length) of pellet. The mean values for DM, OM, CP, $\mathrm{EE}, \mathrm{CF}$, and TDN in pellets was found to be $94.67,83.00,37.01,1.83,5.54$, and $86.69 \% \mathrm{DM}$, respectively, whereas PDI was $92.18 \%$ (tumbling method) and $90.74 \%$ (regression equation). Furthermore, an equation was developed for predicting PDI from nutrient composition and pellet dimensions using multiple linear regression: PDI $(\%)=25.51-$ $2.41 \times$ diameter $(\mathrm{mm})+35.05 \times$ length $(\mathrm{cm})-2.62 \times$ moisture $(\%)+0.99 \times$ nitrogen-free extractives $(\%)$ having $\mathrm{R}^{2}=$ $72.14 \%$. The dairy supplement pellets with a different proportion of protected soybean meal and selenium showed similar nutrient contents, but higher in PDI compare with the control. Moreover, this study, for the first time, deduces that reasonably good prediction of pellet quality in terms of PDI could be possible with the simple measures like chemical composition, pellet diameter and length, which is expected to benefit feed manufacturers and dairy farmers.
\end{abstract}

Keywords: Dairy feeds, nutrient composition, pellet durability index, protected soybean meal.

\section{INTRODUCTION}

Pelleting is a one of feed processing that applies moisture and heat combined with pressure to agglomerate smaller particles into larger particles [1,2]. Its proven benefits include the improved palatability and hygienic condition of feed, the increased feed bulk density and flowability, the elimination of segregation problems, and the improved transportation efficiency. Pelleting also affects the metabolic and digestion characteristics of feeds [3,4]. However, the interrelations between conditioning, pelleting, and cooling should be considered when evaluating the effects of the pelleting process on feed materials [5]. It is also important to understand how the inherent structure of feed is affected by pelleting process, and how pelleting-induced structural changes affect nutrient profiles and availability in dairy cattle (e.g., energy value, protein and carbohydrate fractions, true nutrient supply in rumen and small intestine) [6]. On the other hand, protected soybean meal supplementation 
have an evidence that affected the dairy cows' productivity.

Production of commercial feeds in the form of steamed pellets is increasingly gaining popularity and as a potential technology application in developed countries and Indonesian dairy feed industry. An important criteria to evaluate the quality of pellets is nutrient composition after pelleting and the pellet durability index (PDI) that measures the proportion of intact pellets and fines or broken pellets. This becomes crucial from both consumer appraisal point of view as well as maintaining nutritional worth of the formulated feed such that maximum intact pellets are desired. Factors like inherent characteristics of ingredients used in the formulation, fat level as well as production engineering aspects like conditioning and die specifications etc. dictate PDI [7]. In this aspect, the present investigation was planned to screen dairy feed pellets with a different proportion protected of soybean meal (P-SBM) and selenium (Se) in terms of nutrient composition, PDI, diameter, lenghts of pellet, and in turn to predict the PDI by a regression equation.

\section{MATERIAL AND METHODS}

\subsection{Preparation of Protected Soybean Meal}

The preparation of protected soybean meal was carried out using formaldehyde. The formaldehyde treated was carried out on soybean meal following the method of Rochijan [8]; which applied $0.8 \% / \mathrm{kg}$ DM of formaldehyde to treated/protect soybean meal. The formaldehyde solution was evenly sprayed on the soybean meal and stirred. Furthermore, the treated soybean meal was fermented for one night and aerated the next day for two to three days.

\subsection{Formulation and Analysis of Pellet}

Formulation and process of pelleting is presented in Table 1 and Figure 1. The chemical compositions of pellet sample (P0 - P5) were analyzed in triplicate by AOAC method [9] consisting of moisture content, dry matter (DM), organic matter (OM), crude protein $(\mathrm{CP})$, crude fibre $(\mathrm{CF})$, extract ether (EE), and total digestible nutrients (TDN).

The PDI was determined using Holmen pellet tester (NHP 100, Holmen ${ }^{\circledR}, \quad \mathrm{UK}$ ) as manufacturer's instructions. Briefly, about $100 \mathrm{~g}$ of fresh pellets were weighed and placed inside pellet tester and allowed to circulate within pellet chamber using pneumatic pressure at $70 \mathrm{mBar}$ pressure for $120 \mathrm{sec}$ and PDI calculated. In addition, pellet diameter and lengths were measured manually.

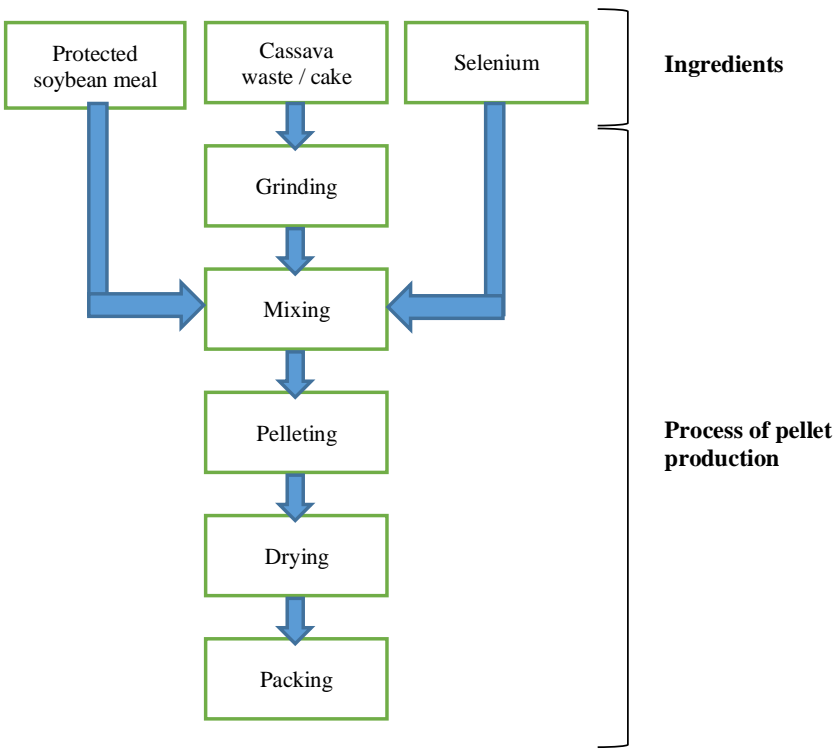

Figure 1 Process of pelleting.

\subsection{Statistical Analysis}

The data obtained were examined by one way ANOVA analysis continued to Duncan Multiple Range Test (DMRT); and a stepwise forward multiple linear regression analysis to predict PDI value.

\section{RESULTS AND DISCUSSION}

Pellets are cylindrical feeds that come from stamping feed raw materials using a die machine. Thus the form of pellet become cylindrical or small pieces with different diameters, lengths and degrees of hardness. Large pellets generally contain fibre derived from forages. Pellet feed for ruminants including dairy cows can be in the form of supplement pellets, concentrate pellets, hay pellets, and complete pellet feed [10]. Feed in the form of pellets is a form of preservation of feed ingredients in a form that is more guaranteed in the level of procurement and continuity of supply to maintain feed quality [11]. There are feedstuff materials that pellet well and produce a durable pellet, and there are others that will not. The advantages of printing pelleted feed include the

Table 1. Formulation of dairy supplement pellet in study (\%DM)

\begin{tabular}{|c|c|c|c|c|c|c|}
\hline \multirow{2}{*}{ Ingredients } & \multicolumn{6}{|c|}{ Formula } \\
\hline & PO & P1 & P2 & P3 & P4 & P5 \\
\hline Protected soybean meal & 90.0 & 89.8 & 89.6 & 89.4 & 89.2 & 89.0 \\
\hline Cassava waste / cake & 10.0 & 10.0 & 10.0 & 10.0 & 10.0 & 10.0 \\
\hline Selenium & - & 0.2 & 0.4 & 0.6 & 0.8 & 1.0 \\
\hline
\end{tabular}


Table 2. Nutrient composition, pellet durability index and pellet form

\begin{tabular}{|c|l|l|l|l|l|l|l|}
\hline \multirow{2}{*}{ Parameter } & \multicolumn{2}{|l|}{ Formula } \\
\cline { 2 - 8 } & P0 & P1 & P2 & P3 & P4 & P5 & Average \\
\hline Nutrient composition: & & & & & & & \\
\hline Moisture (\%) & 4.59 & 4.92 & 5.64 & 5.89 & 5.65 & 5.31 & $5.33 \pm 0.49$ \\
\hline Dry matter (\%) & 95.41 & 95.08 & 94.36 & 94.11 & 94.35 & 94.69 & $94.67 \pm 0.49$ \\
\hline Organic matter (\%DM) & 84.39 & 83.71 & 82.49 & 81.99 & 82.44 & 82.96 & $83.00 \pm 0.90$ \\
\hline Crude protein (\%DM) & 38.06 & 36.80 & 36.75 & 36.80 & 36.47 & 37.16 & $37.01 \pm 0.56$ \\
\hline Extract ether (\%DM) & 2.10 & 2.43 & 1.77 & 2.02 & 1.62 & 1.02 & $1.83 \pm 0.48$ \\
\hline Crude fibre (\%DM) & 5.40 & 5.43 & 5.63 & 5.48 & 5.61 & 5.71 & $5.54 \pm 0.13$ \\
\hline TDN (\%DM) & 86.67 & 86.45 & 86.72 & 86.69 & 86.89 & 86.74 & $86.69 \pm 0.14$ \\
\hline Pellet attributes (test): & & & & & & & \\
\hline PDI with tumbling method (\%) & $87.11^{\mathrm{a}}$ & $92.98^{\mathrm{b}}$ & $92.25^{\mathrm{b}}$ & $93.55^{\mathrm{b}}$ & $93.04^{\mathrm{b}}$ & $94.14^{\mathrm{b}}$ & $92.18 \pm 2.56$ \\
\hline PDI with regression equation (\%) & $87.79^{\mathrm{a}}$ & $90.26^{\mathrm{b}}$ & $90.79^{\mathrm{b}}$ & $89.91^{\mathrm{b}}$ & $94.19^{\mathrm{b}}$ & $90.82^{\mathrm{b}}$ & $90.74 \pm 8.34$ \\
\hline Pellet diameter (mm) & 11.13 & 11.00 & 11.09 & 10.76 & 10.91 & 11.02 & $10.99 \pm 0.35$ \\
\hline Pellet length (cm) & 1.74 & 1.91 & 1.88 & 1.82 & 1.85 & 1.89 & $1.85 \pm 0.28$ \\
\hline
\end{tabular}

${ }^{\mathrm{a}, \mathrm{b}}=$ Means with different superscript within the same row are significantly different $(\mathrm{P}<0.05)$;

TDN = Total digestible nutrients;

PDI = Pellet durability index;

$\% \mathrm{DM}=\%$ dry matter.

following: 1) Increase feed density; 2) Simplify product handling; 3) Reducing the formation of dust; 4) Reducing shrinkage due to scattering; 5) More resistant to damage during storage; 6) Do not provide opportunities for livestock to choose the type of food they like; 7) Increase the amount of feed consumption; 8) Increase palatability; 9) Increase ration conversion; 10) Lowering the cost of feeding; and 11) Ruminants can take advantage of a larger number and type of forage.

The nutrient composition, PDI, and physical of pellet with a different proportion of protected soybean meal and selenium was presented in Table 2. Based on the results of pellet composition analysis, it showed that no significant difference between treatments; mean values for DM, OM, CP, EE, CF, and TDN were 94.67, 83.00, $37.01,1.83,5.54$, and $86.69 \% \mathrm{DM}$, respectively. A similar trend was noted for PDI that varied widely between 87.11 to $94.19 \%$ with the mean PDI of $92.18 \%$ (tumbling method) and $90.74 \%$ (regression equation). Furthermore, multiple linear regression predicting PDI revealed the following equation with $\mathrm{R}^{2}=72.14 \%$.

$$
\begin{aligned}
\text { PDI }(\%)= & 25.51-2.41 \times \text { diameter }(\mathrm{mm})+35.05 \times \\
& \text { length }(\mathrm{cm})-2.62 \times \text { moisture }(\%)+0.99 \times \\
& \text { nitrogen-free extractives }(\%) .
\end{aligned}
$$

The factors that affect the quality of pellets include the following: 1. formulation and dietary nutritional composition; 2. feedstuff particle size; 3. mash conditioning; 4. feed rate; 5 . feed moisture content; 6 . conditioning time and temperature; 7. die speed and compression rate of pellet die; 8 . die specifications (design); 9. gap between the pellet press roll and die; and
10. Other factors $[12,13]$. While the factors that affect the nutritional composition-quality of pellets include the following:

1. Starch, when heated with water, will undergo gelatinization and this functions as an adhesive, thus affecting the strength of the pellets;

2. Fibre, serves as a pellet framework, which will affect the die and roller on the pellet machine;

3. Oil serves as an ingredient that facilitates the formation of pellets. Oil is an energy source with a high metabolic energy. The presence of oil, in addition to supplying energy sources, is also needed to simplify the process of making feed because it can facilitate the release of feed when passing through the filter of feed making machines, it can also improve the quality of feed products, especially feed in the form of pellets and crumbles;

4. Raw materials that have gone through milling and sieving will then be fed into the mixer using a screw. The mixing is done by adding additives (vitamins and minerals) into feed ration. Besides that, Palm Olein as an energy source for animal feed added into the mixture. It acted as a colorant in pelleted feed and also as a fragrance enhancer in pelleted feed [14].

Based on the results of pelleting durability index analysis, the results were significantly different between P0 and P1, P2, P3, P4, P5. This may be due to mineral content on the pellet formulation. Some research examine that mineral source affected pellet mill performance and pellet quality. Diet containing ammonium polyphosphate as a mineral source required significantly more electrical 
energy and enhanced pellet durability [13], although the Selenium affect need to further investigate.

The raw material significant affect the quality of the pellets. The content of natural adhesives (for example starch), protein, fibre, minerals, and fats from the raw material will affect the quality of the pellets. Barley, wheat, canola, and rape seed meal contain natural adhesives that form a physical-chemical bond during processing to produce better quality pellets. However, outside the European region where a lot of wheat and rape seed meal are used as the main ingredients, feed concentrate that uses a lot of grains (corn or sorghum), and soybean meal have low adhesion. In many cases, feed supplement formulations are based on the least cost and optimal cost methods which do not take into account the pelletability of each raw material. Apart from the choice of raw material, other management techniques offer cost effective measures to improve pellet quality. Feed containing large amounts of coarse grains requires extra handling due to particle size, conditioner, die condition, and fat content [15]. Actually, there are numerous factors that affect pellet quality and many are inter-related. It takes a great deal of effort to determine what changes to make and how other aspects of the system or operation might be affected.

\section{CONCLUSION}

The dairy supplement pellets with a different proportion of protected soybean meal and selenium showed similar nutrient contents, but higher in PDI compare with the control. Moreover, this study, for the first time, deduces that reasonably good prediction of pellet quality in terms of PDI could be possible with the simple measures like chemical composition, pellet diameter and length, which is expected to benefit feed manufacturers and dairy farmers.

\section{AUTHORS' CONTRIBUTIONS}

All authors contributed equally to the manuscript.

\section{ACKNOWLEDGMENTS}

This study was supported by PTUPT Grant 2021 from the Directorate of Resources Affairs, the Directorate General of Higher Education, Research, and Technology, the Ministry of Education, Culture, Research, and Technology, Republic of Indonesia (KEMDIKBUDRISTEK-RI) and Universitas Gadjah Mada.

\section{REFERENCES}

[1] E.R. Skoch, K.C. Behnke, C.W. Deyoe, S.F. Binder, The effect of steam-conditioning rate on the pelleting process, in: Animal Feed Science and Technology, vol. 6, 1981, pp. 83-90. DOI: https://doi.org/10.1016/0377-8401(81)90033-X

[2] D. Falk, Pelleting Cost Centre, in: Feed Manufacturing Technology III. R. R. Mcellhiney, ed. American Feed Manufacturers Association, Arlington, VA, 1985, pp. 167-190.

[3] M. Thomas, A.F.B. van der Poel, Physical quality of pelleted animal feed 1. Criteria for pellet quality, in: Animal Feed Science and Technology, vol. 61, 1996, pp. 89-112. DOI: https://doi.org/10.1016/0377-8401(96)00949-2

[4] M.R. Abdollahi, V. Ravindran, B. Svihus, Pelleting of broiler diets: An overview with emphasis on pellet quality and nutritional value, in: Animal Feed Science and Technology, vol. 179, 2013, pp. 1-23. DOI: https://doi.org/10.1016/j.anifeedsci.2012.10.011

[5] M. Thomas, D.J. Van Zuilichem, A.F.B. Van der Poel, Physical quality of pelleted animal feed. 2. Contribution of processes and its conditions, in: Animal Feed Science and Technology, vol. 64, 1997, pp. 173-192. DOI: https://doi.org/10.1016/S0377-8401(96)01058-9

[6] P. Yu, Plant-based food and feed protein structure changes induced by gene-transformation, heating and bio-ethanol processing: A novel synchrotronbased molecular structure and nutrition research program, in: Molecular Nutrition \& Food Research, vol. 54, 2010, pp. 1535-1545. DOI: https://doi.org/10.1002/mnfr.201000178

[7] K.C. Behnke, Feed manufacturing technology: current issues and challenges, in: Animal Feed Science and Technology, vol. 62, 1996, pp. 4957. DOI: https://doi.org/10.1016/S03778401(96)01005-X

[8] Rochijan, Effect of Supplementation Rumen Undegraded Protein on Production and Reproduction Dairy Cows, in: Thesis M.Sc. Faculty of Animal Science, Universitas Gadjah Mada, Yogyakarta, Indonesia, 2014.

[9] AOAC International, Official Methods of Analysis of AOAC International, in: AOAC International, Rockville, Maryland, USA, 2016.

[10] M.E. Ensminger, J.E. Oldfield, W.W. Heinemann, Feed and Nutrition, in: The Ensminger Publishing Company, California, Clovis, USA, 1990.

[11] J.W. Mathius, A.P. Sinurat, D.M. Sitompul, B.P. Manurung, Azmi, Pengaruh bentuk dan lama penyimpanan terhadap kualitas dan nilai biologis pakan komplit, in: Prosiding Seminar Nasional 
Teknologi Peternakan dan Veteriner, 2006, pp. 57-66.

[12] R. Colovic, D. Vukmirovic, R. Matulaitis, S. Bliznikas, V. Uchockis, V. Juskiene, J. Levic, Effect of die channel press way length on physical quality of pelleted cattle feed, in: Food \& Feed Research, vol. 37, 2010, pp. 1-6. Available at: http://foodandfeed.fins.uns.ac.rs/uploads/Magazi nes/magazine_37/effect-of-die-channel-pressway-length-on-physical-quality-of-pelletedcattle-feed.pdf

[13] K.C. Behnke, Factors affecting pellet quality, in: Feed Pelleting Reference Guide, Section 5: Pellet Durability, Kansas State University, Texas, USA, 2019. Available at: https://www.feedstrategy.com/wpcontent/uploads/2019/09/5-

19_Factors_affecting_pellet_quality.pdf

[14] Y. Retnani, Proses Produksi Pakan Ternak, in: Ghalia Indonesia, Bogor, Indonesia, 2011.

[15] W.A. Dozier, Kualitas Pellet Pakan Unggas Pedaging, in: Unggas Indonesia, Membangun Industri Perunggasan Nasional Mandiri, Feed International, 2001. Available at: http://siauwlielie.tripod.com/art_005_02.htm 